\title{
ZMOT marketing strategy during the Covid-19 pandemic
}

\author{
M. Jannah \\ Trunojoyo Madura University, Bangkalan, Indonesia
}

\begin{abstract}
During the Covid-19 pandemic, customers spend their time finding information online. The process of getting a new customer begins with ZMOT (zero moment of truth). This study aims to analyze the ZMOT marketing strategy applied in the Google search engine. The descriptive quantitative approach was used with spread questionnaires by an online survey. The sampling technique used for this study is purposive sampling. The result of this study showed that a majority of customers look for spot tourism on ZMOT Google. Customers started their process about 2-3 weeks before and spent a week making their purchase decision. Instagram is another source they use before confirming their decision.
\end{abstract}

\section{INTRODUCTION}

In recent times, customers have found it convenient to express their needs and wants. Digitalization gives more power to the customer and makes the businessman think about how to win the market. The businessman must explore the consumers' needs, wants, and motivations of buying, which is an important thing.

The moment of truth was started by A.G. Lafley, chairman and CEO of Procter \& Gamble (2005). The first moment of truth is the customers' initial thoughts. The customers have the capability of knowing about a product in the first 3-7 seconds of seeing it. The first moment of truth is the moment customers choose the product instead of the competitor's product (Wikipedia.org). There are also the second moment of truth, the third moment of truth, and the zero moment of truth.

The zero moment of truth is a term coined by Google in 2011. Google introduced the term to represent winning the customers. If in the traditional model there are a stimulus, the first moment of truth, and second moment of truth in sequence before the purchase decision, then the modern model has the zero moment of truth before the first moment of truth.

The internet has an important role in ZMOT (Zero Moment OfTruth). ZMOT catch the ignorance of customer from digital life and prevail on all industry, goods, and services, and it is not just a store but also e-commerce too, B2C and C2C. It does not stop there. ZMOT relates to customer loyalty too.

Businessmen must be aware that the goal of relationship marketing is customer loyalty. When customers are satisfied, they give more advantage to the company (Anderson \& Srinivasan, 2011). They help get new consumers through positive word of mouth, and some have a blog and review the products. Google, Bing, Yandex, CC Search, Swisscows, DuckduckGo, StartPage, Search Encrypt, Wiki.com are examples of search engines.

Google attracts a lot of users. It did even more during the Covid-19 Pandemic. Early in 2020, the world was shocked by the spread of Covid-19, which was later declared a pandemic. Covid-19 is a hot topic, especially in discussions regarding world economic growth. IMF stated that the world economy grew negatively by 4.9 percent in 2020 (money.compas.com). Being no exception, Indonesia was one of the countries that were severely affected by the Covid-19 pandemic. Badan Pusat Statistik (BPS) noted that in the second quarter period, Indonesian's economic growth contracted to 5.32 percent. 
Contraction of economic growth, both of world and Indonesia, had no effect on search engines, especially Google. During the pandemic, Google witnessed an increase in traffic. Their company generated a profit of 2.5 billion in March 2020 (tekno.compas.com). On the zero moment of truth, consumers have more control on finding information about their products on the internet. They can make their minds before purchase decision or going to shop.

In this era, buyers are getting smarter and more critical. They trust the public's recommendation more than sellers'. This research will analyze the ZMOT marketing strategy, describe findings obtained from Google users, and answer the questions such as when the customers decide to buy a product. Factors regarding the sites on Google were captured as ZMOT strategy marketing.

\section{LITERATURE REVIEW}

\subsection{Zero moment of truth}

Procter \& Gamble observed that the first seven seconds was the critical moment before the purchase decision was made. A moment of truth can be described as a stimulus to the consumer to discover the brand in question (Ertemel \& Basçı, 2015).

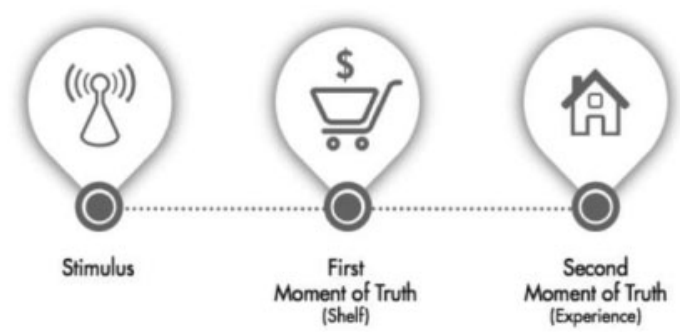

Figure 1. Traditional mental model of the decision-making process.

Source: Lecinski (2011).

Traditionally, the decision-making process started with a stimulus. Lafley, as the P\&G CEO, described the opportunity of the company and brand to be the winner of a booth of truth, first and second moment. The first moment occurs at the store when consumers buy a product. The second occurs at their home. They try the product and decide whether they are satisfied or not. The new mental model of decision making is different. Digitalization and technology are making the consumer smarter. Consumers begin their path of decision making of a purchase in the digital world; it is called the zero moment of truth (ZMOT). They search for product information every time and everywhere. Consumers use the internet to get product and brand information before making a purchase decision (Venkatesan, et al. 2007).

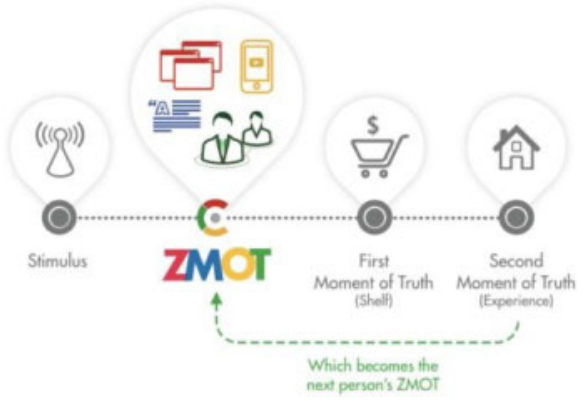

Figure 2. The new mental model of the decision-making process. Source: Lecinski (2011). 


\section{RESEARCH MODEL}

\subsection{Data collections}

The data were collected from online participants. For this exploration, non-probability technique sampling was used, wherein no all members of the population have an equal chance. Purposive sampling was used in this research. This research has some criteria on the sampling (Cooper \& Schindler, 2011): (1) Google users; (2) browsing a product or brand during the Covid-19 pandemic; and (3) minimum 17 years old. The final sample consisted of 363 samples with $32 \%$ male and $68 \%$ female.

\subsection{The questionnaire}

The questionnaire captured demography, age, and gender of the respondents. Income and job were also captured by this questionnaire to describe findings obtained from Google users using the ZMOT marketing strategy.

The researcher gives more items on the questionnaire for capturing the factor of sites on a search engine Google as ZMOT marketing strategy. In this part, a five-point Likert type scale was used ( 1 = "strongly disagree", 5 = "strongly agree").

\section{RESULT AND DISCUSSION}

This research will cover Google users during the Covid-19 pandemic as a ZMOT marketing strategy. Most of the respondents in this research were female $(68 \%)$, and $32 \%$ were male. This indicates that during the Covid-19 pandemic, females spend more time than males to get product and brand information from Google.

Table 1. Age of respondents.

\begin{tabular}{lrr}
\hline Age & Total & \% \\
\hline $\mathbf{1 7 - 2 5}$ years old & 195 & $54 \%$ \\
$\mathbf{2 6}-\mathbf{3 5}$ years old & 117 & $32 \%$ \\
$\mathbf{3 6 - 4 5}$ years old & 39 & $11 \%$ \\
$\mathbf{> 4 5}$ years old & 12 & $3 \%$ \\
Total & 363 & $100 \%$ \\
\hline
\end{tabular}

Table 1 shows that the majority of the participants in this study are the $\mathrm{Z}$ Generation, that is, those who are 17 to 25 years old (people born in 1995-2020). These findings are similar to those of prior research by Grencíková \& Vojtovic (2017), who observed that Generation Z are spending more time Googling product information than $\mathrm{X}$ and $\mathrm{Y}$ generations.

This study also captures the factors as an antecedent of the sites on Google as a ZMOT marketing strategy. The researcher tries to get the factors of expected site participants. This study uses exploratory factor analysis, KMO MSA $>0.5$, and Barlett's test $(<0.05)$ (Hair et al.,2010). The results are shown in Table 2.

Table 2. KMO and Bartlett's test.

\begin{tabular}{lll}
\hline Kaiser-Meyer-Olkin Measur Adequacy. & e of Sampling & .882 \\
Bartlett's Test of Sphericity & Approx. Chi-Square df & 2324.95991 \\
& Sig. & .000 \\
\hline
\end{tabular}


Table 2 describes that KMO MSA $0.882(>0.5)$ and the Bartlett's test sig. $0.000(<0.05)$ fulfill the requirements of exploratory factor analysis.

This Study has 14 items of measured expected sites as ZMOT. From 14 items divided by 3 factors or variables can good ZMOT as a marketing strategy from Google. The 14 items are:

$\mathrm{X} 1$ Sites have a complete description of goods/ services

$\mathrm{X} 2$ Sites have a picture of the goods/services

X3 Sites show goods and services and people's comments

X4 Sites have no advertisement

X5 Sites have good privacy

X6 We can communicate directly with persons

$\mathrm{X} 7 \quad$ Site has a good design and layout

X8 Site provides accurate information

X9 Site uses the correct language

X10 Site provides interesting and relevant information

X11 Site has popular and paid domain extensions (eg. .com; .co.id; or .net)

$\mathrm{X} 12$ Site has a good speed

$\mathrm{X} 13$ Site is responsive

$\mathrm{X} 14$ Site is easy to understand

The 14 items are divided into 3 variables or factors. First, variables X1, X2, X7, X8, X9, X10, $\mathrm{X} 12, \mathrm{X} 13$, and $\mathrm{X} 14$ are site design; second, variables $\mathrm{X} 3, \mathrm{X} 6$, and $\mathrm{X} 11$ are site social, and the variables $\mathrm{X} 3$ and $\mathrm{X} 4$ are site privacy.

\section{CONCLUSION}

The big question is why tourism spots became the first option, although Indonesia had a lockdown policy. From the exploratory factor analysis, we get 3 variables from 14 items; they are site design, site social, and site privacy on the Google site as a ZMOT marketing strategy. From the result of this study, we know that a recommendation website as a ZMOT marketing strategy can be good for a startup business. The companies must emphasize several points before creating a website, keeping site design, site social, and site privacy in mind to connect with consumers.

\section{REFERENCES}

Anderson, R.E., \& Srinivasan, S.S. (2003) 'E-satisfaction and e-loyalty: a contingency framework', Psychology And Marketing, Vol. 20 No. 2, pp. 123-138.

Cooper \& Schindler. 2011. Business Research Methods 11thed. New York: McGraw-Hill

Ertemel, A.V., \& Basçı, A. (2015) 'Effect of Zero Moment of Truth on Consumer Buying

Decision: An Exploratory Research in Turkey', International Journal of Social Science and Education Research, Vol. 1 No. 2, pp. 526-526.

Hair, J. F., William. C. B., Barry. J. B., \& Rolph. E A. (2010) Multivariate Data Analysis: A Global Perspective, Seventh Ed, Pearson Education Inc. The United States of America.

Lecinksi, J. (2011). Winning the zero moment of truth. Zero Moment of Truth

Venkatesan, R., V. Kumar, \& Nalono R., (2007), 'Multichannel Shopping: Causes and Consequences, Journal of Marketing, Vol. 71 No. 2, pp. 114-132. Wikipedia.org

money.compas.com

tekno.compas.com 